\title{
Integrity test of lead apron and its effect on personnel and carers
}

\author{
Omojola Akintayo Daniel and Isiodu Chinonye Xaviera
}

\begin{abstract}
Article Info
Department of Radiology, Medical Physics Unit, Federal Medical Center Asaba, Delta State, Nigeria (OAD); Department of Radiography and Radiological Sciences, College of Health Science and Technology, Nnamdi-Azikiwe University Nnewi, Anambra State, Nigeria (ICX)

For Correspondence:

Omojola Akintayo Daniel

akintayoomojola@gmail.com

Received:

16 January 2018

Accepted:

Available Online:

21 February 2018

5 March 2018

ISSN: 2224-7750 (Online) 2074-2908 (Print)

DOI: 10.3329/bsmmuj.v11i1.35360

Keywords:

Carer; Lead apron; Radiation worker

Cite this article:

Daniel OA, Xaviera IC. Integrity test of lead apron and its effect on personnel and carers. Bangabandhu Sheikh Mujib Med Univ J. 2018; 11: 34-37.

Copyright:

The copyright of this article is retained by the author(s) [Atribution CC-By 4.0]

Available at:

www.banglajol.info

A Journal of Bangabandhu Sheikh Mujib Medical University, Dhaka, Bangladesh
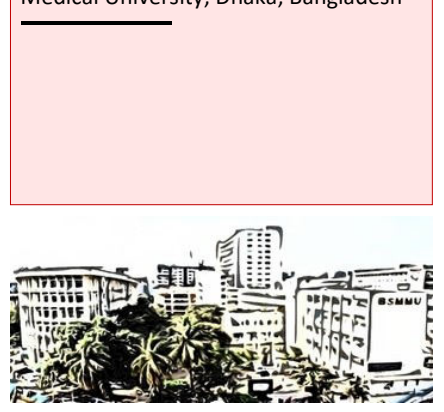

Abstract they are replaced.

\section{Introduction}

The use of X-ray equipment requires that appropriate shielding should be put in place. Shielding refers to radiation protection and to materials that have the ability to absorb large amount of ionizing radiation, usually $\mathrm{X}$-rays and Gamma rays. The categories of shielding include fixed, mobile, and personal shielding. Fixed shielding includes the thickness of walls, which should have a lead equivalence of 1 to $3 \mathrm{~mm}$, the doors, and protective cubicles. Mobile shielding is appropriate during fluoroscopy procedures in which radiation personnel remains near the patient. Personal shielding includes lead apron, gloves, thyroid shield, and glass spectacles. $\underline{1,2}$ Of interest to us in this study is the lead apron which serves the purpose of protecting and shielding radiation worker and patient relative (carer) who assist in holding unstable patient during examination from the potentially harmful effects of ionizing radiation. Studies have shown that lead aprons are usually kept carelessly in the X-ray room after use. X-ray departments that have racks and hangers hardly return them back and those that do not have in most of the cases leave them on table bucky of the X-ray machine or they are thrown on the lead screens or barrier after use, this in turn damages the internal structure of the lead and renders it ineffective for future use. $.3-5$
\end{abstract}

The use of lead apron is known to protect radiation workers and carers (patient relatives) from scatter radiation. The study intends to assess the integrity of lead apron by checking for defects and to estimate the mean dose rate to personnel and carers and also to compare the percentage mean absorbance of the apron with the related studies. Ten lead aprons were used involving three vendors. A fluoroscopy unit, floor mounted X-ray unit, survey meter, lead aprons and meter rule were used. Crack and tear were identified with some areas close to the critical organ site. Seventy percent of the aprons showed signs that they were defective. Correlation of the lead aprons mean age and the total number of defective lead aprons were not significant $(p=0.866)$. The mean thickness of the aprons for the three brands affected the percentage absorbance $(p<0.001)$. The mean dose rate was above $20 \mathrm{mSv}$ per year recommended for radiation workers averaged over 5 years. It is recommended that the defective apron close to the critical organ be replaced and those in areas distal from the critical organs be further evaluated using the rejection criteria test before

The use of lead protective apron should be of recommended specification based on the X-ray output, procedure or examination. Lead protective apron must be provided for all staff carrying out X-ray procedures where a fixed protective barrier is not made available like in the interventional procedures for orthopedic surgeries. It is expected that lead apron must have minimum attenuation of $0.35 \mathrm{~mm}$ lead for the front section and not less than $0.25 \mathrm{~mm}$ of lead for the remaining parts. It should be designed to cover at least the front part of the body from the throat downwards and including the knees, the entire breast bones and shoulders. It should also cover the sides of the body from not more than $10 \mathrm{~cm}$ below the armpit to at least half way down the thigh; and the back from the shoulder blades down to and including the knees. It is expected that lead protective apron should be tested for shielding integrity on receipt/purchase and thereafter at approximately 12-18 month intervals. Each apron should be given an individual identification number, which should not be removed. Testing for imperfections in an apron can be achieved by physical investigation. A further test using fluoroscopy on a floating table bucky or by radiography should be carried out if doubt about the integrity of the apron is suspected. This will quickly show faults, holes and apron deterioration. It is also expected that if there is any doubt about an apron, it should 

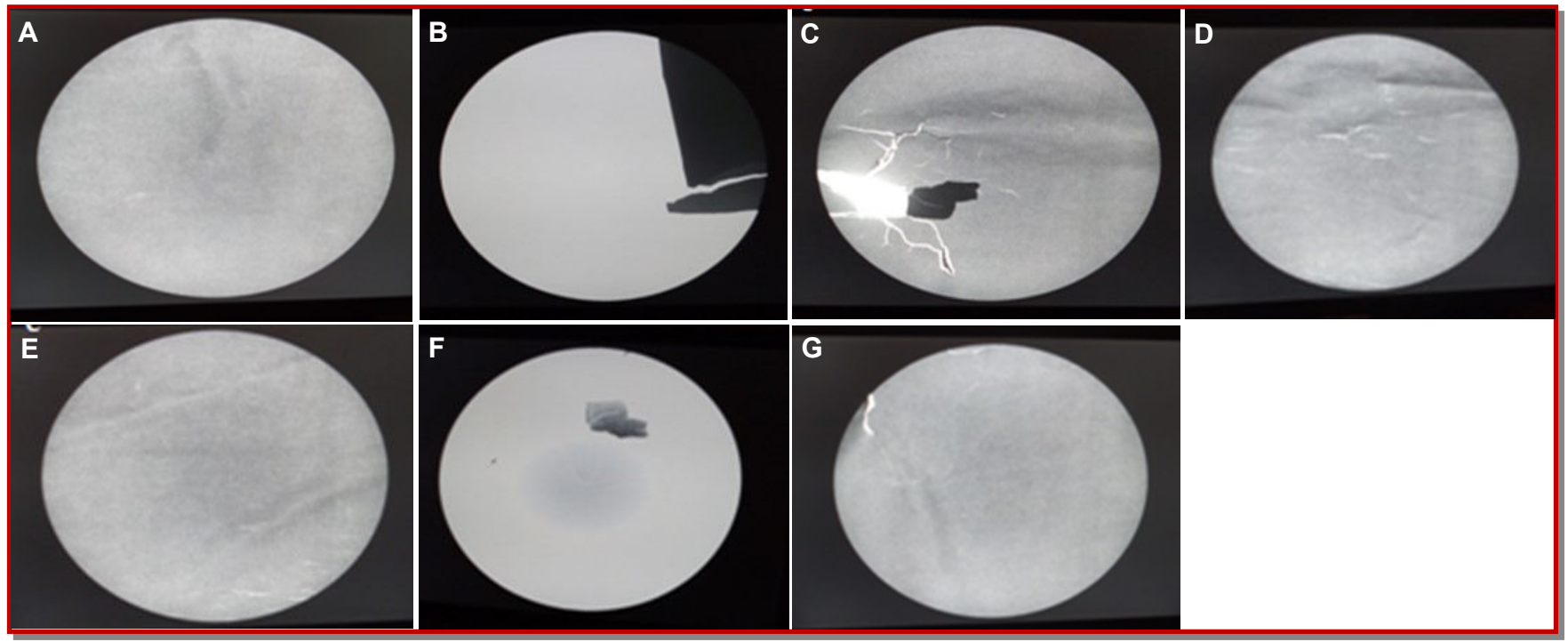

Figure 1: Photograph showing a normal lead apron (A); lead aprons showing cracks and tears (B-G)

be withdrawn from use until further investigation is obtained. If damage to an apron is seen or suspected, it should be reported immediately. The date on which the testing took place should be logged against the individual identification number for that lead protective apron for future reference. $.6,7$

Studies by Kicken and Bos (1995) and Aldridge et al. (1997) have shown that lead apron with $0.5 \mathrm{~mm}$ thickness has the ability to attenuate 98 to $99.5 \%$ of the radiation dose, whereas the $0.25 \mathrm{~mm}$ thickness attenuates approximately $96 \%$ of the dose. $.8,9$ In another study by Oyar and Kışlalığlu (2012), the $0.25 \mathrm{~mm}$ lead equivalent apron on the average had $95 \%$ absorbance, whereas the $0.5 \mathrm{~mm}$ lead equivalent apron demonstrated permeability on average of $99 \%$ absorbance. 10 On this basis, it was recommended that radiation worker should not receive more than $20 \mathrm{mSv}$ per year average over a period of 5 years and the general public dose should not exceed $1 \mathrm{mSv}$ in a single year. $\underline{.11-14}$

The aim of this study was to check if the integrity of the lead apron was still intact. The study also intended to estimate the mean dose rate to personnel mostly radiologist who worked three times a week to perform special procedures with Xray facilities and to carers who assisted their patients. It was discovered on the average that three carers would come around to assist their patients in a week and would use the lead apron at least once in a year.

\section{Materials and Methods}

This prospective study was carried out over a period of two weeks which involved the use of a Precision RXI static General Electric fluoroscopy unit with energy output of $150 \mathrm{kVp}$, a floor mounted X-ray unit with energy output of $125 \mathrm{kVp}$ and tube current of $500 \mathrm{mAs}$, a RadEye ${ }^{\mathrm{TM}}$ B20-ER survey meter, lead aprons and meter rule. Three brands of lead apron totalling 10 were used. The RadEye $^{\mathrm{TM}}$ B20-ER multi-purpose survey meter has the capacity to measure alpha, beta, gamma, and Xrays. The measuring range of the survey meter was 0-100 mSv/hour (0-10 Rem/hour), energy range of $17 \mathrm{keV}-1.3 \mathrm{MeV}$, and a detector made of Pancake GM-tube, of window diameter $44 \mathrm{~mm}, 1.8-2.0 \mathrm{mg} /$ $\mathrm{cm}^{2}$.

In this study, the RadEye ${ }^{\mathrm{TM}}$ B20-ER Multi-Purpose Survey Meter was used to measure Instantaneous Dose Rate (IDR) placed $30 \mathrm{~cm}$ just behind the lead apron to measure the scatter radiation using the broad beam geometry in which the lead apron was more distal from the source (X-ray machine tube head) and proximal to the detector (RadEye ${ }^{\mathrm{TM}} \mathrm{B} 20$ ER Multi-Purpose Survey Meter). The IDR was further used to calculate the Time-Average Dose Rate (TADR) which was taken as eight hours per day and was used to determine the dose per year.15, 16 The mean total number of days, the radiologist and carer would spend per year using the lead apron was approximately 157 days (3 times a week over one year). The technical factor used on the conventional X-ray unit was $100 \mathrm{kVp}$ and $20 \mathrm{mAs}$ for distance of $80-120 \mathrm{~cm}$. The fluoroscopy machine was used to acquire images of the lead apron by placing them on the table bucky to detect for crack, hole and tear (Figure 1). Rejection criteria used were based on the recommendation by the Australian/ New Zealand Standard (AS/NZS 4543.3:2000) IEC 61331-3 protective devices against diagnostic medical X-radiation. Part 3 which state that apron should be replaced if there were defects over the non-critical areas for which the sum of all defects 


\begin{tabular}{|c|c|c|c|}
\hline \multicolumn{4}{|c|}{ Table I } \\
\hline \multicolumn{4}{|c|}{ Lead apron used for this study and their equivalent thickness } \\
\hline \multirow[t]{2}{*}{ Lead apron } & \multicolumn{2}{|c|}{ Lead equivalent } & \multirow{2}{*}{$\begin{array}{l}\text { Mean number of } \\
\text { years in use }\end{array}$} \\
\hline & Front protection & Back protection & \\
\hline \multirow[t]{4}{*}{ A (wrap around) } & 0.35 & 0.35 & \\
\hline & 0.35 & 0.25 & 5 \\
\hline & 0.50 & 0.50 & \\
\hline & 0.35 & 0.25 & \\
\hline \multirow[t]{3}{*}{ B (wrap around) } & 0.35 & 0.25 & \\
\hline & 0.35 & 0.25 & 7 \\
\hline & 0.50 & 0.35 & \\
\hline \multirow[t]{3}{*}{ C (front only) } & 0.35 & - & \\
\hline & 0.50 & - & 3 \\
\hline & 0.25 & - & \\
\hline
\end{tabular}

\begin{tabular}{|lccc|}
\hline \multicolumn{3}{|c|}{ Table II } \\
\hline \multicolumn{3}{|c|}{ \%Defective lead apron with respect to the side } \\
\hline Lead apron & Not defective & \multicolumn{2}{c|}{ Defective } \\
\cline { 3 - 4 } & & Front & Back \\
\hline A $(n=4)$ & 1 & 2 & 3 \\
B $(n=3)$ & 2 & 1 & 1 \\
C (n=3) & 0 & 3 & 0 \\
\hline
\end{tabular}

exceeds $670 \mathrm{~mm}^{2}$, or the equivalent of a $29 \mathrm{~mm}$ diameter circular hole. If the defects were over critical areas, such as the gonads or thyroid, apron should be replaced if the sum of the defected exceeds $11 \mathrm{~mm}^{2}$, or the equivalent of a $3.8 \mathrm{~mm}$ diameter circular hole. The criteria could not be fully used to categorize if a lead apron should be replaced but was useful for the case of critical organ areas. The age of the lead apron used were between 3-7 years (Table I).

\section{Results}

The number of defective lead apron in brand A (wrapped around) was 3 out of 4 . The number of defective lead apron B (wrapped around) was 1 out

\begin{tabular}{|cccc|}
\hline \multicolumn{5}{|c|}{ Table IV } \\
\hline \multicolumn{5}{|c|}{ Comparison of \%mean attenuation of 0.25, } \\
0.35 and 0.50 mm of lead \\
\hline $\begin{array}{c}\text { Lead } \\
\text { thickness } \\
(\mathrm{mm})\end{array}$ & \multicolumn{3}{c}{ \% Mean attenuation } \\
\hline \multicolumn{5}{c}{ This } & Kicken \& & Oyar \& \\
0.25 & study & Bos & Kislaliglu \\
0.35 & 84.4 & 96 & 95 \\
0.50 & 89.4 & - & - \\
\hline
\end{tabular}

of 3 whereas the number of defective lead apron $C$ (front side only) was 3 out of 3 . The result show that $70 \%$ of the total lead apron used was defective (Table II).

Indirect measurement of scatter radiation using lead apron A, B and C at a distance of range $80-120 \mathrm{~cm}$ from the source gave rise to mean instantaneous dose rate (IDR), time-average dose rate (TADR) and annual dose rate (ADR) of $0.02 \mathrm{mSv} /$ hour, $0.1 \mathrm{mSv}$ / day and $21.7 \mathrm{mSv} /$ year; $0.02 \mathrm{mSv} /$ hour, $0.2 \mathrm{mSv} /$ day and $24.7 \mathrm{mSv} /$ year; $0.03 \mathrm{mSv} /$ hour, $0.2 \mathrm{mSv} /$ day and $33.4 \mathrm{mSv} /$ year respectively (Table III). This study percentage mean attenuation from the radiation source for lead brand $\mathrm{A}, \mathrm{B}$ and $\mathrm{C}$ were $84.4,89.4$ and 92.3 at lead thickness of $0.25-0.50 \mathrm{~mm}$ (Table VI).

\section{Discussion}

Three major lead thicknesses were used in the Department of Radiology investigated in this study which includes $0.25,0.35$ and $0.50 \mathrm{~mm}$ of lead Majority of the lead aprons with front protection was $0.35 \mathrm{~mm}$ and those with back protection were $0.25 \mathrm{~mm}$. This study shows that only three $(30 \%)$ of the lead aprons out of the ten investigated aprons were not defective and $70 \%$ showed signs of being defective. A more critical investigation show that some of the defective areas in the lead aprons were close to the lower part of the aprons which had critical organs like the gonads with higher tissue weighting factor. A defective few were towards

\section{Table III}

\begin{tabular}{|c|c|c|c|c|c|c|}
\hline Lead apron & $\mathrm{kVp}$ & mAs & $\begin{array}{l}\text { Distance } \\
(\mathrm{cm})\end{array}$ & $\begin{array}{l}\text { Mean IDR } \\
\text { (mSv/hour) }\end{array}$ & $\begin{array}{c}\text { Mean TADR } \\
(\mathrm{mSv} / \text { day })\end{array}$ & $\begin{array}{l}\text { Mean ADR } \\
\text { (mSv/year) }\end{array}$ \\
\hline A & 100 & 20 & $80-120$ & 0.02 & 0.1 & 21.7 \\
\hline B & 100 & 20 & $80-120$ & 0.02 & 0.2 & 24.7 \\
\hline $\mathrm{C}$ & 100 & 20 & $80-120$ & 0.03 & 0.2 & 33.4 \\
\hline
\end{tabular}


other region. Based on Lambert and McKeon model some of the defects observed in our study did not exceed the $670 \mathrm{~mm}^{2}$ for reject and replacement. Lead apron B mean age was above Lambert and McKeon mean age of 5 years. 7 Correlation of the mean number of years in use and the number of defective lead aprons were not significant $(p=0.866)$

Similarly, the mean thickness of lead for brand A (0.36), B (0.34) and C (0.37) against mean IDR show that there was statistically significant difference $(\mathrm{p}<$ 0.001). This result show that lead thickness had significant impact on the percentage absorbance of the lead

The percentage mean attenuation for $0.25 \mathrm{~mm}$ of lead in this study (84.4) was lower compared those of Kicken and Bos- whose percentage attenuation for $0.25 \mathrm{~mm}$ of lead was 96 and Oyar and Kışlalığlu 10 whose percentage attenuation for 0.25 $\mathrm{mm}$ of lead was 95. Difference was also noticed for the \% mean attenuation for the $0.50 \mathrm{~mm}$ of lead which was 92 against that of Kicken and Bos 8 whose percentage attenuation for $0.50 \mathrm{~mm}$ of lead was 99.5 and Oyar and Kışlalıoğlu10 whose percentage atenuation for $0.5 \mathrm{~mm}$ of lead was 99 . The reason for this disparity could be attributed to the kind of detector used and technical factors used.

In a single year, it was estimated from our study that radiologist will receive an average of $26.6 \mathrm{mSv}$ based on the calculated \%absorbance of the lead aprons used in this study and it is seen to be higher than the recommended dose limit of $20 \mathrm{mSv}$ per year for radiation workers averaged for 5 years. It is estimated that a carer on the average will use the lead apron once in a year which implies that he/she will receive $0.021 \mathrm{mSv}$ in a year which was seen to be below $1 \mathrm{mSv}$ in a single year.

\section{Conclusion}

Proper ways of handling lead apron after use should be taught. Regular check of lead apron should be encouraged since there no physical ways to ascertain tear or crack except through the use of X-ray.

\section{References}

1. Chung BA, Benzon HT. Essential of pain medicine. $3^{\text {rd }}$ edi. Fluoroscopy and radiation safety, 2011, p 502-10.

2. Iball GR, Kennedy EV, Brettle DS. Modelling the effect of lead and other materials for shielding of the fetus in CT pulmonary angiography. $\mathrm{Br} \mathrm{J}$ Radiol. 2008; 81; 966: 499-503.

3. Nkubli BF, Nzotta CC, Nwobi IC, Moi SA, Luntsi G, Salisu U, Matthew A. Quality control in radiology units of tertiary healthcare centers in North Eastern Nigeria. NJMIRT. 2013; 2: 26-31.

4. Karami V, Zabihzadeh M, Shams N, Saki Malehi A. Gonad shielding during pelvic radiography: A systematic review and meta-analysis. Arch Iran Med. 2017; 20: 113-23.

5. Eze CU, Abonyi LC, Njoku J, Irurhe NK, Olowu O. Assessment of radiation protection practices among radiographers in Lagos, Nigeria. Niger Med J. 2013; 54: 386-91.

6. Protective devices against diagnostic medical Xradiation. Part 3: Protective clothing and protective devices for gonads. AS/NZS 4543.3:2000

7. Lambert K, McKeon T. Inspection of lead aprons: Criteria for rejection. Health Phys. 2001; 80: S67- 69.

8. Kicken PJ, Bos AJ. Effectiveness of lead apron in vascular radiology: Result of clinical measurements. Radiology 1995; 197: 473-78.

9. Aldridge HE, Chisholm RJ, Dragatakis L, Roy L. Radiation safety in the cardiac catheterization laboratory. Can J Cardiol. 1997; 13: 459-67.

10. Oyar O, Kışlalığlu A. How protective are the lead aprons we use against ionizing radiation? Diagn Interv Radiol. 2012; 18: 147-52.

11. International Atomic Energy Agency (IAEA). Applying radiation safety standards in diagnostic radiology and interventional procedures using Xrays. Safety Reports Series No. 39. Vienna IAEA Publication, 2006.

12. International Atomic Energy Agency (IAEA). Radiation protection and safety of radiation sources: International basic safety standards. IAEA safety standards series No. GSR Part 3 (Interim): Vienna IAEA Publication, 2011.

13. The 2007 recommendations of the International Commission on Radiological Protection. ICRP Publication 103. Ann ICRP. 2007; 37: 1-332.

14. The 1990 recommendations of the International Commission on Radiological Protection. ICRP Publication 60. Ann ICRP. 1991; 21: 1-201.

15. Institute of Physics and Engineering in Medicine (IPEM). Medical and dental guidance notes. York: IPEM Publication, 2002.

16. Work with Ionizing Radiation. Ionizing Radiation Regulation (IRR) 1999. Approved code of practice and guidance. London: Health and Safety Executive (HSE) Publication, 2000, p 63-68. 